\title{
Non cardiac chest pain (NCCP)
}

\begin{abstract}
Non-cardiac chest pain (NCCP) is a common clinical problem however the pathophysiology remains poorly understood. Until the pathophysiology is more clearly understood, certain patients with NCCP continue to experience chest pain and seek frequent medical attention. This mini-review will discuss the underlying pathophysiology of NCCP including gastrooesophageal reflux, oesophageal dysmotility and visceral hypersensitivity. Furthermore, it aims to highlight the current treatment options based on the current literature.
\end{abstract}

Keywords: non-cardiac chest pain, NCCP
Volume 5 Issue 7 - 2016

\author{
Pearson JS, ' Whorwell PJ ${ }^{2}$ \\ 'Neurogastroenterology Unit, University Hospital of South \\ Manchester, UK \\ ${ }^{2}$ Centre for Digestive Diseases, University of Manchester, UK
}

Correspondence: James Pearson, Neurogastroenterology Unit, University Hospital of South Manchester, M23 9LT, UK, Tel 016I 29I 4177,Email james.pearson@manchester.ac.uk

Received: August 11, 2016 | Published: December 16, 2016
Abbreviations: DOS, diffuse oesophageal spasm; GORD, gastro oesophageal reflux disease; NCCP, non-cardiac chest pain; PPI, proton pump inhibitor; TCA's, tricyclic antidepressants

\section{Introduction}

Non-cardiac chest pain (NCCP) is defined as recurring, anginalike, retrosternal chest pain of non-cardiac origin. In a pooled meta-analysis, the global prevalence of NCCP was reported at $13 \% .{ }^{1}$ Patient history and symptoms are not sufficient to distinguish between cardiac and non-cardiac causes of chest pain. ${ }^{2}$ It is primarily important to investigate whether the chest pain is of cardiac aetiology. If a cardiological explanation for the chest pain has been eliminated, patients are often referred to for investigations into a gastroenterological causation of pain.

The pathophysiology of NCCP remains to be fully elucidated. Numerous factors have been found to be responsible for NCCP including, gastro-oesophageal reflux disease (GORD), oesophageal motility disorders, abnormal processing of oesophageal stimuli, altered autonomic activity and visceral hypersensitivity. Some of the underlying mechanisms have been extensively studied e.g. GORD, however, the other potential causes remain under-researched. It is plausible that a multitude of mechanisms interact with each other in the individual patient further complicating the clinical picture. A greater understanding of the underlying pathophysiology will help to improve the diagnosis and the treatment of this condition. This review aims to describe the potential causes of NCCP along with current treatment strategies and highlight the need for further research.

\section{Discussion}

\section{The diagnosis of NCCP}

The ROME III diagnostic criteria for functional chest pain of a presumed oesophageal origin are as follows; The patient must have fulfilled the following symptoms for at least the previous three months with symptom onset at least six months prior to diagnosis of: midline chest pain or discomfort that is not of burning quality, absence of evidence that gastroesophageal reflux is the cause of the symptom and absence of histopathology-based oesophageal motility disorders. ${ }^{3}$
Clinically, the initial definition of "recurring, angina-like, retrosternal chest pain of non-cardiac origin" is often labelled as NCCP.

\section{Clinical evaluation of patients with chest pain}

Exclusion of cardiac disease is of primary important in the evaluation of a patient presenting with chest pain. History and clinical presentation alone have been found to be inaccurate in predicting coronary artery disease. ${ }^{4}$ The nature of cardiac investigations performed typically depends on the patients, age, family history, risk factors and local procedures. Most patients will undergo an exercise tolerance test and functional imaging with some patients progressing to coronary angiography dictated by the NICE guidelines. ${ }^{5}$ After exclusion of a cardiac aetiology, patients may be tested for gastrooesophageal reflux disease (GORD). Not all patients will undergo upper gastro-intestinal endoscopy and this is of limited value as the presence of oesophagitis is only inferential of GORD and endoscopy has been found to be normal in more than $80 \%$ of cases in patients presenting with $\mathrm{NCCP}^{6,7} \mathrm{pH}$ monitoring is the gold standard in diagnosing GORD. If this test is not performed, a therapeutic trial of acid suppressive medication may be the most effective diagnostic tool available. Other than oesophageal manometry, there are no routinely conducted diagnostic tests in the diagnosis of NCCP.

\section{The proposed mechanisms underlying NCCP}

A variety of factors have been implicated in the pathogenesis of NCCP including GORD, oesophageal dysmotility, musculoskeletal problems, psychological factors and visceral hypersensitivity. There is some evidence to suggest that infusion of acid into the oesophagus can reduce coronary blood flow in patients with coronary artery disease. ${ }^{8}$ It seems reasonable to assume that none of these factors are mutually exclusive in the individual patient and therefore may act in a synergistic nature leading to symptomatology.

\section{Gastro-oesophageal reflux disease (GORD)}

The most common cause of NCCP is GORD and an abnormal 24hour $\mathrm{pH}$ test has been reported in up to $62 \%$ of patients with NCCP. ${ }^{9}$ GORD is present when the gastric contents enter into the distal oesophagus causing symptoms or damage to the oesophageal mucosa (oesophagitis). Acid suppressive medication is highly effective 
and safe in the treatment of most patients with GORD. The typical symptoms of GORD are heartburn and indigestion. There are other atypical symptoms of GORD such as dysphagia, chronic cough and NCCP. ${ }^{10}$ The acid perfusion (Bernstein) test was previously popular in predicting GORD related chest pain but has shown to be insensitive when compared to ambulatory $\mathrm{pH}$ monitoring and is no longer clinically used. In a study of 75 patients with NCCP, the Bernstein test was found to have a specificity of $90 \%$ but a sensitivity of $36 \%$ for acid-related chest pain. ${ }^{11,12}$

Extensive research has been undertaken into the link between GORD and NCCP. There is conflicting data into the role of GORD in NCCP with around $20 \%$ of patients with NCCP reporting chest pain in relation to an acid reflux event during ambulatory 24 hour $\mathrm{pH}$ studies. ${ }^{13-15}$ There are controversies in the reporting of 24 hour ambulatory $\mathrm{pH}$ studies in patients with NCCP, however, it seems likely that if the patient reports a chest pain symptom which is demonstrated to be linked to a reflux event then a certain degree of the patients symptoms are caused by GORD. Treatment of GORD is fairly simple and this may provide the most sensitive test in determining whether or not a patient's NCCP is caused by GORD.

\section{Treatment of GORD in NCCP}

Clinically, the majority of patients with GORD receive PPI's as an empirical treatment. Studies have shown that in patients with NCCP, PPI therapy has been shown to be effective at relieving chest pain symptoms. A PPI test has been proposed by Fass et al. ${ }^{14}$ this differs to empirical therapy in that a large dose is given for a short period of time. GORD is the primary cause of NCCP therefore a strategy such as this one makes clinical sense. This is backed up by numerous studies outlined below.

A double blinded placebo controlled trial comparing omeprazole (20mg b.d.) to placebo demonstrated that the PPI was superior at controlling chest pain compared to placebo, $86 \%$ compared to $6 \% .^{16}$
The largest trial of acid suppressive therapy on NCCP comparing esomeprazole (40mg b.d.) to placebo showed that esomeprazole was statistically better at controlling chest pain than placebo. The authors demonstrated better control of chest pain in patients who had pain less than two times a week but not in those who had pain more than two times a week. Esopmprazole improved symptoms in $33.1 \%$ of the patients. The differences observed in this study may be attributable to the exclusion of patients who clinically had GORD, how these patients were excluded i.e. due to a positive 24 hour $\mathrm{pH}$ test, endoscopyically, Bravo capsule or clinical judgement etc. is not known. ${ }^{17}$ A number of previous studies have been reported using different PPIs and patient outcomes. A summary of these can be found in Table 1. Clinically, it seems sensible to undertake an empirical PPI trial in patients presenting with NCCP as the first course of action if they have not undergone 24 hour $\mathrm{pH}$ monitoring.

Other acid suppressive medications have been trialled in the treatment of NCCP. Fass et al. ${ }^{14}$ conducted a placebo controlled trial comparing omeprazole to placebo for one week in 37patients with NCCP. $78 \%$ of GORD patients reported a positive response and $14 \%$ of non-GORD patients reported a response and improvement in their chest pain. ${ }^{9}$ Since this study a number of other studies have been reported using different PPIs and patient outcomes. This seems a reasonable outcome in lieu of the fact that up to $62 \%$ of patients with NCCP have GORD.

Ranitidine, a $\mathrm{H} 2$ receptor antagonist, has been investigated in two studies for the treatment of GORD related NCCP. Stahl et al found that Ranitidine in 13 patients improved chest pain in all the patients after eight weeks treatment. ${ }^{19}$ Achem et al..$^{20}$ demonstrated that in patients with nutcracker oesophagus reducing oesophageal acid exposure using either omeprazole or ranitidine and found positive results. ${ }^{20}$ These results suggest that in NCCP patients where GORD is likely to be the cause that a therapeutic trial of acid suppressive medication is warranted as first line treatment.

Table I Acid suppressive medication for the treatment of NCCPI8

\begin{tabular}{|c|c|c|c|c|c|}
\hline Author, year & Patients (n) & Trial & Medication dose & Duration & Outcome \\
\hline Achem et al. ${ }^{16}$ & 12 & Open label & $\begin{array}{l}\text { Ranitidine I50q.m.s / } \\
\text { omeprazole } 20 \mathrm{mg} \text { b.d }\end{array}$ & 8weeks & $83 \%$ improvement \\
\hline Stahl et al. ${ }^{19}$ & 13 & Open label & Ranitidine I50q.m.s & 8weeks & I00\% improvement \\
\hline Achem et al. ${ }^{16}$ & 36 & $\begin{array}{l}\text { Double-blinded, } \\
\text { placebo controlled }\end{array}$ & Omeprazole $20 \mathrm{mg}$ b.d & 8weeks & $81 \%$ improvement vs $6 \%$ \\
\hline Chambers et al. 1998 & 23 & Open label & Omeprazole 40mg qhs & 6weeks & $\begin{array}{l}\text { Improvement but complete } \\
\text { improvement in only } 30 \%\end{array}$ \\
\hline Borjeson et al. 2003 & 19 & $\begin{array}{l}\text { Double-blinded, } \\
\text { placebo controlled, } \\
\text { crossover }\end{array}$ & $\begin{array}{l}\text { Lansoprazole } 30 \mathrm{mg} \text { b.d } \\
\text { vs. placebo }\end{array}$ & 8weeks & $\begin{array}{l}\text { Significant reductions in pain } \\
\text { intensity and duration were } \\
\text { registered during the study. } \\
\text { Symptom relief did not change } \\
\text { significantly vs placebo }\end{array}$ \\
\hline Flook et al. ${ }^{17}$ & 599 & $\begin{array}{l}\text { Double-blinded, } \\
\text { placebo controlled }\end{array}$ & $\begin{array}{l}\text { Esomeprazole } 40 \mathrm{mg} \text { b.d } \\
\text { vs. placebo }\end{array}$ & 4weeks & $\begin{array}{l}\text { esomeprazole improvement } 33.1 \% \\
\text { vs } 24.9 \%(P=0.035)\end{array}$ \\
\hline
\end{tabular}




\section{4 hour $\mathrm{pH}$ impedance monitoring}

The introduction of impedance $\mathrm{pH}$ monitoring into practice allows clinicians to monitor the exact $\mathrm{pH}$ of a reflux episode i.e. whether it is acidic $(\mathrm{pH}<4)$, weakly acidic $(\mathrm{pH} 4-7)$ or non-acid $(\mathrm{pH}>7)$. The extent of the reflux into the proximal oesophagus can also be measured along with its clearance time. The role of non-acid reflux in NCCP has only been evaluated in one abstract. Vial et al. ${ }^{21}$ reviewed the impedance traces of 28 patients presenting with NCCP undergoing $\mathrm{pH}$ impedance testing. A reflux event with a $\mathrm{pH}>4$ was classed as non-acidic reflux and only events lasting $>3$ seconds were classed as reflux episodes. During the impedance study, 24patients experienced chest pain, 9patients were taking a PPI, and the remaining 15 were taking no acid suppressive medication. The 24patients experienced a combined total of 293 episodes of chest pain during the study. In the group taking a PPI, $24.5 \%$ of patients experienced a reflux event related to chest pain of which $20 \%$ were acidic and $80 \%$ were nonacid reflux events. In the group who were not taking PPI's, $36.6 \%$ of patients experienced chest pain related to a reflux event of which $64 \%$ of those were acidic with the remaining $36 \%$ being non-acidic impedance events. ${ }^{21}$

This is the only study reporting on the role on non-acid reflux in NCCP. Further work is required in order to evaluate the role of nonacidic reflux events in NCCP, the authors classed any episode with a $\mathrm{pH}>4$ as non-acidic but it is unknown whether any of these events were strictly alkaline or whether all reported events were "weakly acidic" reflux. This has the potential to be a difficult study to replicate as to date there is no standardised reporting of $\mathrm{pH}$ impedance studies and different equipment will have different protocols, reporting methods and the software will analyse the data in different ways. It is unclear whether these patients experienced typical symptom of heartburn or an angina like pain experienced by patients with NCCP. This is a single-centre trial with small numbers; further studies are required in order to evaluate the potential role of non-acid reflux in NCCP and the utilisation of $\mathrm{pH}$ impedance studies in NCCP.

\section{Oesophageal dysmotility}

Oesophageal dysmotility has been found to play a role in the pathogenesis of NCCP. Dekel et al. found $30 \%$ of patients with NCCP had an underlying oesophageal motility disorder diagnosed on oesophageal manometry testing. ${ }^{22}$ There is some controversy as to which is the most common oesophageal dysmotility disorder found in NCCP. Katz et al. ${ }^{23}$ reported on 910 patients referred for oesophageal motility with NCCP to 251patients referred with dysphagia. The majority of NCCP patients had normal motility (72\%) with the remaining $28 \%$ classed as having a motility disorder. Out of the abnormal motility patients, nutcracker oesophagus was the most common disorder affecting $48 \%$ of the patients whereas in the dysphagia group, only $10 \%$ of patients had nutcracker oesophagus. ${ }^{23}$ Dekel et al. ${ }^{24}$ reported on 587 patients presenting for oesophageal manometry with NCCP or dysphagia. A normal manometry report was the most common finding (70\%). The most common manometric dysmotility finding in the NCCP group was a hypotensive lower oesophageal sphincter (LOS) $(61 \%)$ with $10 \%$ of patients having a hypertensive LOS, $10 \%$ having a nutcracker oesophagus and a further $10 \%$ having a non-specific oesophageal dysmotility problem. The remainder of patients having ineffective peristalsis $(5 \%)$, achalasia $(2 \%)$ or diffuse oesopghageal spasm $(2 \%){ }^{24}$

\section{Treatment of oesophageal dysmotility related NCCP}

There is a complex relationship between oesophageal motility disorders and GORD which is not fully understood. Clinically, this can make the treatment of oesophageal dysmotility disorders difficult. Treatments of NCCP related oesophageal dysmotility have had mixed results. Several trials have examined the role of pharmacological intervention in the treatment of NCCP attributed to spastic motor disorders. Unfortunately, most of the studies have included a small sample size and few are well designed randomised placebo controlled trials.

\section{Nitrates in the treatment of NCCP}

Nitrates have been used in the treatment of DOS and have shown relief of pain after short term administration. These trials have been small-scale observational trials and no placebo controlled trials have been carried out in order assess the efficacy of these compounds. ${ }^{25,26}$ One study has examined the utility of phosphodiesterase -5 inhibitors in the treatment of oesophageal dysmotility related NCCP. The study took 11 patients with a range of oesophageal dysmotility problems and administered sildenafil. The manometric pattern was improved in nine of the patients however symptomatology only improved in four patients. Two of these patients discontinued the medication due to side effects. ${ }^{27}$ A single case report described improvements with various phosphodiesterase- 5 inhibitors in DOS..$^{28}$ There is a lack of well-designed trials evaluating the effectiveness of these compounds in both oesophageal motility disorders and NCCP.

\section{Calcium channel blockers in the treatment of NCCP}

There are a small number of studies evaluating the efficacy of calcium channel blockers in NCCP. In the eight studies that have been performed on patients with DOS, an improvement was found by the majority of authors..$^{29-36}$ The trial with the largest number of patients included found that 12 out of 18 study participants diagnosed with DOS radiologically improved after administration of nifedipine with the other 6participants having other organic diseases.${ }^{32}$ Radiologically, the sensitivity and specificity for diagnosing DOS is low.

There is one randomised controlled trial comparing nifedipine to placebo in patients with nutcracker oesophagus. ${ }^{37}$ This demonstrated that oral nifedipine reduced manometric contraction amplitudes compared to placebo. However symptomatology was not improved over a 14 week crossover trial. One trial assessed the efficacy of diltiazem in a randomised cross over trial however the trial only included 14 subjects and was found to be effective in improving symptoms whereas another study found conflicting results with no benefit in its treatment of DOS. 38,39

The effectiveness of calcium channel blockers is NCCP is unclear. Current data is lacking on their clinical utilisation and effectiveness and larger well-designed trials of a longer duration are required in order to determine whether these are an effective treatment of NCCP.

\section{Endoscopic injection of botulinum toxin in NCCP}

Only one double-blind, randomised, cross-over trial reported on the use of Botulinum toxin in NCCP in the literature. ${ }^{40}$ This identified 11 patients with diffuse oesophageal spasm and compared an injection of botulinum toxin $(100 \mathrm{U})$ to a saline injection of the same volume. The botulinum injection improved patients dysphagia however had no effect on their chest pain. Other studies reporting on the use of 
botulinum toxin in NCCP have been small observational studies. These are summarised in the Table 2. There is one well designed randomised, cross-over trial comparing the use of botulinum toxin with placebo and only one trial in the literature had resolution of chest pain as the primary outcome..$^{40,41}$ The role of botulinum toxin injections in oesophageal motility disorders is not well understood and there is a paucity of trials comparing botulinum toxin against placebo in oesophageal dysmotility. Well designed, large, placebo controlled trials are required in order to establish whether injection of botulinum toxin has an effect in patients with NCCP which is caused by an oesophageal dysmotility condition..$^{42-45}$

Table 2 The use of botox in NCCP

\begin{tabular}{|c|c|c|c|c|c|}
\hline Author. year & Patients (n) & Indication & Dose & Result & Comments \\
\hline Miller at al. ${ }^{4 I}$ & 15 & $\begin{array}{l}\text { Motility disorders } \\
\text { (non-achlastic) }\end{array}$ & $80 U$ & \multicolumn{2}{|c|}{$\begin{array}{l}\text { After } 10.6 \text { months mean follow-up } 33 \% \text { remair } \\
67 \% \text { required repeat endoscopic treatments. }\end{array}$} \\
\hline $\begin{array}{l}\text { Nebendahl et } \\
\text { al. }{ }^{45}\end{array}$ & 3 & DOS & $\begin{array}{l}1000 \\
\text { 4quadrants at } 5 \text { levels }\end{array}$ & \multicolumn{2}{|c|}{ All patients reported symptom improvement } \\
\hline $\begin{array}{l}\text { Nebendahl et } \\
\text { al. }{ }^{43}\end{array}$ & 9 & DOS & $260 U$ & \multicolumn{2}{|c|}{$\begin{array}{l}\text { Initial symptom improvement in all patients. } \\
\text { At } 6 \text { months, } 7 \text { patients remained symptom free. }\end{array}$} \\
\hline Storr et al. ${ }^{42}$ & 9 & DOS & $\begin{array}{l}\text { I00U - multiple sites distal } \\
\text { oesophagus, I-I.5 cm interval. }\end{array}$ & \multicolumn{2}{|c|}{$\begin{array}{l}\text { At } 6 \text { months, } 8 \text { patients had symptom improvement. } \\
4 \text { required repeat treatment to remain in remission. }\end{array}$} \\
\hline Miller et al. ${ }^{41}$ & 29 & $\begin{array}{l}\text { Spastic motility } \\
\text { disorders }\end{array}$ & $N / A$ & $\begin{array}{l}72 \% \text { experienced symptom } \\
\text { improvement. } \\
6 \text { patients required a third } \\
\text { dose to remain in remission. }\end{array}$ & $\begin{array}{l}\text { No manometric data reported. } \\
\text { Primary outcome was } \\
\text { improvement of chest pain. }\end{array}$ \\
\hline
\end{tabular}

\section{Visceral hypersensitivity}

Visceral hypersensitivity has long been proposed as a cause of NCCP. To date, studies have focussed on balloon distension of the oesophagus. Studies have suggested that patients with NCCP demonstrate altered central processing of oesophageal stimuli. ${ }^{46}$

Richter et al. first demonstrated differences in visceral sensations between patients with chest pain of an unknown aetiology and asymptomatic controls. ${ }^{47}$ This was conducted using an intraoesophageal balloon and asking patient to note when they experienced pain, the control subjects experienced pain at insufflation of greater than $8 \mathrm{ml}$ compared to those with chest pain of an unknown aetiology of whom $50 \%$ experienced chest pain at lower insufflations. Rao et $\mathrm{al},{ }^{48}$ investigated the relationship between cross-sectional area and pressures generated rather than the volume of balloon distension in order to provoke pain. ${ }^{48}$ They demonstrated that patients with chest pain had a tolerance threshold which was $50 \%$ lower when compared to control subjects. The subjects included in the study underwent upper gastrointestinal endoscopy and $\mathrm{pH}$ monitoring, some were found to have acid sensitivity. Therefore, balloon distension inducing sensitivity of the oesophagus is likely a shared feature of chest pain patients with and without evidence of GORD. This relationship has been proven by studies using acid perfusion into the oesophageal lumen followed by distension studies. ${ }^{49}$

It is likely that these observations explain the reported $40 \%$ of patients who have unexplained chest pain having gastro-oesophgeal related pain and will exhibit abnormal acid exposure times on 24 hour $\mathrm{pH}$ studies. ${ }^{50}$ In patients where acid exposure time is found to be abnormal, they are considered to have GORD as the explanation of their chest pain and as previously discussed, an empirical trial of acid suppressive medication may be warranted. The ROME III foundation suggest that patients who do not exhibit abnormal acid exposure time on 24 hour $\mathrm{pH}$ studies are to be classified as having function chest pain and "distension stimuli assume primary importance in diagnosis". ${ }^{3}$ Despite the body of evidence linking abnormal sensory processing to NCCP, there is no single test for routine use in the diagnosis of NCCP.

Various studies have shown that alterations in the central nervous system (CNS) processing of afferent signals in patients with chest pain have been detected using balloon distension studies. Bradley et al, compared patients with unexplained chest pain to healthy controls, GORD patients, coronary artery disease patients and patients with IBS. Perceptions of oesophageal stimuli were similar between the groups apart from the group with chest pain of an unexplained nature. The author concluded that "errors in central interpretation of afferent signals rather than an increase in peripheral sensitivity is the relevant pathophysiological feature of functional chest pain". ${ }^{51,52}$ Whitehead et al conducted a systematic review of the literature in the evidence of sensory processing being a diagnostic marker for IBS and found that abnormalities in central processing are present in this group of patients. ${ }^{53}$

Together, studies reporting on the role of visceral hypersensitivity in NCCP have focussed on the alterations of sensory processing in the oesophagus following balloon distension studies. Oesophageal balloon distension studies are invasive and distressing for the patient. There is evidence to suggest that a proportion of patients with NCCP are viscerally hypersensitive. If this is the case it stands to reason that they are sensitive throughout the length of the gastrointestinal tract and this is not confined entirely to the oesophagus.

\section{The treatment of visceral hypersensitivity in NCCP}

Numerous studies have aimed to treat NCCP using agents which 
modify visceral sensations. Several trials have evaluated the efficacy of tricyclic antidepressants (TCA's). Cannon et al. ${ }^{54}$ conducted a double-blind placebo controlled trial comparing imipramine against placebo for three weeks in 60 patients with NCCP. They reported a $52 \%$ reduction in chest pain episodes. ${ }^{54}$ Prakash et al reported long term outcomes using TCA's in patients with NCCP. They examined patients who failed to respond to acid suppressive medication. They report that three out of four patients responded at long term follow up to low dose TCA's. Despite the small sample size $(n=21)$ if visceral hypersensitivity can be demonstrated, following an empirical trial of acid suppressive medication, then if visceral hypersensitivity can be demonstrated it seems that TCS's may be an effective treatment modality. ${ }^{55}$ Selective serotonin reuptake inhibitors (SSRI's) have been trialled for use in NCCP. Sertraline was compared to placebo in a placebo controlled trial. It was found that Sertraline significantly reduced pain scores when compared to placebo, however side-effects associated with the use of SSRI's were found in $27 \%$ of patients. ${ }^{56}$

Hypnotherapy has been shown to be effective in patients with functional gastrointestinal disorders such as IBS and functional dyspepsia. ${ }^{57-59}$ Miller et al. ${ }^{58}$ demonstrated the effectiveness of hypnotherapy on patient's quality of life in a small single blind controlled trial, they also demonstrated symptom remission at longterm follow up. ${ }^{60,61}$ The study had several limitations including small numbers and due to the nature of the treatment being offered it is impossible to conduct a placebo controlled trial of such treatment. Despite the study's limitations, it shows a good initial and sustained response and required further investigation in the treatment of NCCP and opens the question as to whether other psychological interventions may be effective in the treatment of NCCP.

\section{Conclusion}

NCCP presents a significant problem for clinicians and is distressing for patients. There is evidence to suggest that patients with NCCP have a good prognosis and a low risk of developing coronary artery disease later in life. ${ }^{62-64}$ Despite this, NCCP patients remain difficult to reassure due to the cardiac connotations of symptomatology. It has been shown that patients with NCCP consult healthcare professionals more frequently than their ischaemic heart disease counterparts. ${ }^{63}$ The mainstay of research in NCCP has focused on the role of GORD as an underlying cause. It seems sensible that once a cardiac cause has been dismissed that patients undergo an empirical trial of acid suppressive medication. If this proves to be ineffective at relieving symptoms then further gastrointestinal investigations are warranted. If these cannot provide an explanation for symptoms then it has been suggested that these patients may be viscerally hypersensitive. Current investigations have not yielded a test which is non-invasive and effective at diagnosing hypersensitivity in these patients and there is clinically a need for such an investigation.

\section{Acknowledgments}

None.

\section{Conflicts of interest}

The authors declare that there are no conflicts of interest.

\section{Funding}

None.

\section{References}

1. Ford AC, Suares NC, Talley NJ. Meta-analysis: the epidemiology of noncardiac chest pain in the community. Alimentary Pharmacology \& Therapeutics. 2011;34(2):172-180.

2. Jerlock M, Welin C, Rosengren A, et al. Pain characteristics in patients with unexplained chest pain and patients with ischemic heart disease. European journal of cardiovascular nursing. Journal of the Working Group on Cardiovascular Nursing of the European Society of Cardiology. 2007;6(2):130-136.

3. Drossman DA. Rome III: the new criteria. Chin J Dig Dis. 2006;7(4):181-185.

4. Nevens F, Janssens J, Piessens J, et al. Prospective study on prevalence of esophageal chest pain in patients referred on an elective basis to a cardiac unit for suspected myocardial ischemia. Dig Dis Sci. 1991;36(2):229-235.

5. NICE. National Clinical Guideline For Acute and Chronic Conditions. 2010.

6. Ho KY, Ng WL, Kang JY, et al. Gastroesophageal reflux disease is a common cause of noncardiac chest pain in a country with a low prevalence of reflux esophagitis. Digestive Diseases and Sciences. 1998;43(9):1991-1997.

7. Frobert O, Funchjensen P, Jacobsen NO, et al. Upper Endoscopy in Patients with Angina and Normal Coronary Angiograms. Endoscopy. 1995;27(5):365-370.

8. Chauhan A, Mullins PA, Taylor G, et al. Cardioesophageal reflex: A mechanism for 'linked angina' in patients with angiographically proven coronary artery disease. J Am Coll Cardiol. 1996;27(7):1621-1628.

9. Fass R, Fennerty MB, Ofman JJ, et al. The clinical and economic value of a short course of omeprazole in patients with noncardiac chest pain. Gastroenterology. 1998;115(1):42-49.

10. Fox M, Forgacs I. Gastro-oesophageal reflux disease. British Medical Journal. 2006;332(7533):88-93.

11. Richter JE, Hewson EG, Sinclair JW, et al. Acid perfusion test and 24 hour esophageal $\mathrm{pH}$ monitoring with symptom index. Comparison of tests for esophageal acid sensitivity. Dig Dis Sci. 1991;36(5):565-571.

12. Paterson WG, Abdollah H, Beck IT, et al. Ambulatory esophageal manometry, pH-metry, and Holter ECG monitoring in patients with atypical chest pain. Dig Dis Sci. 1993;38(5):795-802.

13. Beedassy A, Katz PO, Gruber A, et al. Prior sensitization of esophageal mucosa by acid reflux predisposes to reflux-induced chest pain. Journal of Clinical Gastroenterology. 2000;31(2):121-124.

14. Fass R, Naliboff B, Higa L, et al. Differential effect of long-term esophageal acid exposure on mechanosensitivity and chemosensitivity in humans. Gastroenterology. 1998;115(6):1363-1373.

15. Kushnir VM, Sayuk GS, Gyawali CP. Abnormal GERD Parameters on Ambulatory $\mathrm{pH}$ Monitoring Predict Therapeutic Success in Noncardiac Chest Pain. American Journal of Gastroenterology. 2010;105(5):1032-1038.

16. Achem SR, Kolts BE, MacMath T, et al. Effects of omeprazole versus placebo in treatment of noncardiac chest pain and gastroesophageal reflux. Dig Dis Sci. 1997;42(10):2138-2145.

17. Flook NW, Moayyedi P, Dent J, et al. Acid-Suppressive Therapy With Esomeprazole for Relief of Unexplained Chest Pain in Primary Care: A Randomized, Double-Blind, Placebo-Controlled Trial. American Journal of Gastroenterology. 2013;108(1):56-64.

18. Hershcovici T, Achem SR, Jha LK, et al. Systematic review: the treatment of noncardiac chest pain. Alimentary Pharmacology \& Therapeutics. 2012;35(1):5-14. 
19. Stahl WG, Beton RR, Johnson CS, et al. Diagnosis and treatment of patients with gastroesophageal reflux and noncardiac chest pain. South Med J. 1994;87(7):739-742.

20. Achem SR, Kolts BE, Wears R, et al. Chest pain associated with nutcracker esophagus: a preliminary study of the role of gastroesophageal reflux. Am J Gastroenterol. 1993;88(2):187-192.

21. Vial P, Heckman MG, DeVault KR, et al. Non-Acid Reflux in Noncardiac Chest Pain. Gastroenterology. 2012;42(5):S413.

22. Dekel R, Martinez Hawthorne SD, Guillen RJ, et al. Evaluation of symptom index in identifying gastroesophageal reflux diseaserelated noncardiac chest pain. Journal of Clinical Gastroenterology. 2004;38(1):24-29.

23. Katz PO, Dalton CB, Richter JE, et al. Esophageal Testing of Patients with Noncardiac Chest Pain or Dysphagia-Results of 3 Years Experience with 1161 Patients. Ann Intern Med. 1987;106(4):593-597.

24. Dekel R, Pearson T, Wendel C, et al. Assessment of oesophageal motor function in patients with dysphagia or chest pain-the Clinical Outcomes Research Initiative experience. Alimentary Pharmacology \& Therapeutics. 2003;18(11-12):1083-1089.

25. Parker WA, Mackinnon GL. Nitrites In The Treatment of Diffuse Esophageal Spasm. Drug Intelligence \& Clinical Pharmacy. 1981;15(10):806-807.

26. Orlando RC, Bozymski EM. Clinical And Manometric Effects of Nitroglycerin In Diffuse Esophageal Spasm. New Engl J Med. 1973;289(1):23-25.

27. Eherer AJ, Schwetz I, Hammer HF, et al. Effect of sildenafil on oesophageal motor function in healthy subjects and patients with oesophageal motor disorders. Gut. 2002;50(6):758-764.

28. Agrawal A, Tutuian R, Hila A, et al. Successful use of phosphodiesterase type 5 inhibitors to control symptomatic esophageal hypercontractility: A case report. Digestive Diseases and Sciences. 2005;50(11):2059-2062.

29. Davies HA, Lewis MJ, Rhodes J, et al. Trial of Nifedipine For Prevention Of Esophageal Spasm. Digestion. 1987;36(2):81-83.

30. Davies HA, Lewis M, Rhodes J, et al. Nifedipine For Relief Of Esophageal Chest Pain. New Engl J Med. 1982;307(20):1274.

31. Blackwell JN, Holt S, Heading RC. Effect of Nifedipine On Esophageal Motility And Gastric-Emptying. Digestion. 1981;21(1):50-56.

32. Banciu T, Iova M, Biroasiu G, et al. The diagnostic and therapeutic contribution of calcium channel inhibitors (nifedipine) in esophageal spasm. Medecine interne. 1981;28(1):69-71.

33. Nasrallah SM, Tommaso CL, Singleton RT, et al. Primary esophageal motor disorders-clinical-response to nifedipine. South med J. $1985 ; 78(3): 312-315$.

34. Nasrallah SM. Nifedipine in the treatment of diffuse esophageal spasm. Lancet. 1982;2(8310):1285.

35. Traube M, Hongo M, Magyar L, et al. Effects of nifedipine in achalasia and in patients with high-amplitude peristaltic esophageal contractions. Jama Journal of the American Medical Association. 1984;252(13):1733-1736.

36. Thomas E, Witt P, Willis M, et al. Nifedipine Therapy For Diffuse Esophageal Spasm. South Med J. 1986;79(7):847-849.

37. Richter JE, Dalton CB, Bradley LA, et al. Oral Nifedipine In The Treatment Of Noncardiac Chest Pain In Patients With The Nutcracker Esophagus. Gastroenterology. 1987;93(1):21-28.

38. Richter JE, Spurling TJ, Cordova CM, et al. Effects Of Oral Calcium Blocker, Diltiazem, On Esophageal Contractions - Studies In Volunteers And Patients With Nutcracker Esophagus. Digestive Diseases and Sciences. 1984;29(7):649-656.
39. Cattau EL, Castell DO, Johnson DA, et al. Diltiazem Therapy For Symptoms Associated With Nutcracker Esophagus. American Journal of Gastroenterology. 1991;86(3):272-276.

40. Vanuytsel T, Bisschops R, Mimidis K, et al. A sham-controlled study of injection of botulinum toxin in diffuse esophageal spasm. Gastroenterology. 2008;134(4):A-14.

41. Miller LS, Parkman HP, Schiano TD, et al. Treatment of symptomatic nonachalasia esophageal motor disorders with botulinum toxin injection at the lower esophageal sphincter. Digestive Diseases and Sciences. 1996;41(10):2025-2031.

42. Storr M, Allescher HD, Rosch T, et al. Treatment of symptomatic diffuse esophageal spasm by endoscopic injection of botulinum toxin: a prospective study with long term follow-up. Gastrointest Endosc. 2001;54(6):754-759.

43. Nebendahl JC, Brand B, Von Schrenck T, et al. Treatment of diffuse esophageal spasm with botulinum toxin: A prospective study with 6 months' follow up. Gastrointestinal Endoscopy. 1999;49(4):Ab129.

44. Miller LS, Pullela SV, Parkman HP, et al. Treatment of chest pain in patients with noncardiac, nonreflux, nonachalasia spastic esophageal motor disorders using botulinurn toxin injection into the gastroesophageal junction. American Journal of Gastroenterology. 2002;97(7):1640-646.

45. Nebendahl JC, Brand B, von Schrenck T, et al. Effective treatment of diffuse esophageal spasm (DES) by endoscopic injection of botulinum toxin (BTX). Gastroenterology. 1998;114(4):A240.

46. Barish CF, Castell DO, Richter JE. Graded Esophageal Balloon Distension - a New Provocative Test for Noncardiac Chest Pain. Digestive Diseases and Sciences. 1986;31(12):1292-1298.

47. Richter JE, Barish CF, Castell DO. Abnormal sensory perception in patients with esophageal chest pain. Gastroenterology. 1986;91(4):845-852.

48. Rao SS, Gregersen H, Hayek B, et al. Unexplained chest pain: the hypersensitive, hyperreactive, and poorly compliant esophagus. Ann Intern Med. 1996;124(11):950-958.

49. Hu WH, Martin CJ, Talley NJ. Intraesophageal acid perfusion sensitizes the esophagus to mechanical distension: a Barostat study. Am J Gastroenterol. 2000;95(9):2189-2194.

50. Kahrilas PJ, Quigley EMM. Clinical esophageal $\mathrm{pH}$ recording: A technical review for practice guideline development. Gastroenterology. 1996;110(6):1982-1996.

51. Bradley LA, Scarinci IC, Richter JE. Pain Threshold Levels and Coping Strategies among Patients Who Have Chest Pain and Normal CoronaryArteries. Med Clin N Am. 1991;75(5):1189-1202.

52. Bradley LA, Richter JE, Scarinci IC, et al. Psychosocial and Psychophysical Assessments of Patients with Unexplained Chest Pain. American Journal of Medicine. 1992;92:S65-S73.

53. Whitehead WE, Palsson OS. Is rectal pain sensitivity a biological marker for irritable bowel syndrome: Psychological influences on pain perception. Gastroenterology. 1998;115(5):1263-1271.

54. Cannon RO. Imipramine in Patients with Chest Pain Despite Normal Coronary Angiograms-Reply. New Engl J Med. 1994;331(13):882-883.

55. Prakash C, Clouse RE. Long-term outcome from tricyclic antidepressant treatment of functional chest pain. Gastroenterology. 1999;44(12):2373-2379.

56. Varia I, Logue E, O'Connor C, et al. Randomized trial of sertraline in patients with unexplained chest pain of noncardiac origin. American heart journal. 2000;140(3):367-372.

57. Whorwell PJ. Hypnotherapy for irritable bowel syndrome: the response of colonic and noncolonic symptoms. J Psychosom Res. 2008;64(6):621-623 
58. Miller V, Whorwell PJ. Hypnotherapy for functional gastrointestinal disorders: a review. Int J Clin Exp Hypn. 2009;57(3):279-292.

59. Calvert EL, Houghton LA, Cooper P, et al. Long-term improvement in functional dyspepsia using hypnotherapy. Gastroenterology. 2002;123(6):1778-1785.

60. Miller V, Jones H, Whorwell PJ. Hypnotherapy for non-cardiac chest pain: long-term follow-up. Gut. 2007;56(11):1643.

61. Jones H, Cooper P, Miller V, et al. Treatment of non-cardiac chest pain: a controlled trial of hypnotherapy. Gut. 2006;55(10):1403-1408.

62. Prina LD, Decker WW, Weaver AL, et al. Outcome of patients with a final diagnosis of chest pain of undetermined origin admitted under the suspicion of acute coronary syndrome: A report from the Rochester Epidemiology Project. Ann Emerg Med. 2004;43(1):59-67.

63. Eslick GD, Talley NJ. Non-cardiac chest pain: predictors of health care seeking, the types of health care professional consulted, work absenteeism and interruption of daily activities. Alimentary Pharmacology \& Therapeutics. 2004;20(8):909-915.

64. Marchandise B, Bourassa MG, Chaitman BR, et al. Angiographic evaluation of the natural history of normal coronary arteries and mild coronary atherosclerosis. The American journal of cardiology. $1978 ; 41(2): 216-220$ 